\title{
Strength Reliability of Micro Polycrystalline Silicon Structure
}

\author{
Shigeru Hamada, Kenji Hasizume, \\ Hiroyuki Nakaura and Yoshihide Sugimoto \\ Department of Mechanical Engineering, Faculty of Engineering, Kyushu University \\ Japan
}

\section{Introduction}

Polycrystalline silicon (poly-Si) structure is widely employed in the Micro-ElectroMechanical Systems (MEMS) [Najafi, 2000; Senturia ,2000]. MEMS devices, which contain mechanical movement, have to maintain their reliability in face of external shock, thermal stress and residual stress from manufacturing processes, and fracture will begin mainly in stress concentration area. Therefore, it is necessary to build up reliability design criterion of the poly-Si structure that has stress concentration [Chen et al., 2002; Greek et al.,1997; Kapels et al., 2000; Muhlstein et al., 2004; Namazu et al., 2000; Sharpe et al., 2001; Tsuchiya et al., 1998]. However, since the size effect is large, the microscopic poly-Si depends for the strength on the effective area caused by the stress concentration of structure. Moreover, as the point peculiar to the microscopic poly-Si at the time of thinking of strength, in order that the techniques of processing the upper surface and the sidewall surface differ, it is mentioned that the surface roughness used as the source of a stress concentration differs. It depends for the strength of the microscopic poly-Si also on surface roughness. Therefore, it is necessary to deal with simultaneously the stress concentration of structure and the stress concentration by surface roughness in the case of strength evaluation. In order to clarify the bending strength and its effective area dependability of poly-Si, bending tests using micro scale cantilever beams with or without notch of several sizes are performed. Moreover, surface roughness measurement using AFM is carried out, it determines for the stress concentration by surface roughness, and a quantitative effective area is defined. Fracture origins are specified by fracture surface observation, and the validity of the effective area are shown. Finally, the static strength design criteria in consideration of scattering in strength which used two parameters, the maximum stress and an effective area, are proposed.

\section{Test method}

\subsection{Specimen}

The specimens are illustrated in Fig. 1. Shapes and dimensions of the specimens are shown in Table 1. For bending tests, two types of specimens; Type-A and B are prepared. In the Type-A specimen, the notch of several sizes $(1 \sim 5[\mu \mathrm{m}])$ is introduced in the root section of microcantilever beam. In the Type- $\mathrm{B}$, by the microscopic observation, the $1[\mu \mathrm{m}]$ corner radius is 
recognized indeed in the root section of micro cantilever beam. Thickness of the specimen $(h)$ is 3.5, 6.4 and $8.3[\mu \mathrm{m}]$. The gap between the cantilever and the substrate is $2[\mu \mathrm{m}]$.

The poly-Si is Chemical Vapour Deposited (CVD) on single crystal silicon wafer surface, and the specimens are made from surface micromachining process. The Deep Reactive Ion Etching (DRIE) process were used for processing of the sidewall surface of 6.4, 8.3 [ $\mu \mathrm{m}]$ thickness specimens. Therefore, especially in the specimen side surface made by DRIE, microscopic irregularity called "scarop" which is not seen on the upper surface. Figure 2 shows the example of the scarop for the $6.4[\mu \mathrm{m}]$ thickness specimen.

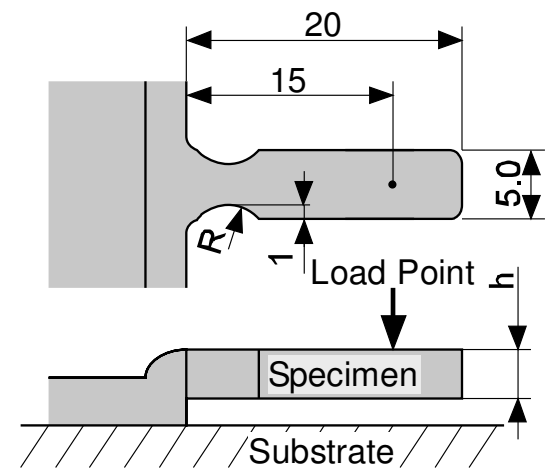

(a) Notched specimen (Type-A)

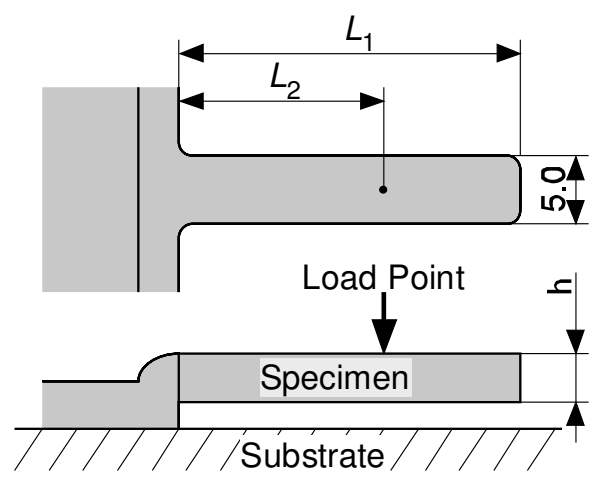

(b) Specimen without notch (Type-B).

Fig. 1. Schematic diagram of the specimens (unit: $\mu \mathrm{m}), h=3.5,6.4,8.3[\mu \mathrm{m}]$

\begin{tabular}{ccccc}
\hline \multicolumn{2}{c}{ Specimen Type } & $L_{1}, \mu \mathrm{m}$ & $L_{2}, \mu \mathrm{m}$ & $R, \mu \mathrm{m}$ \\
\hline Type-A & L15R1 & 20 & 15 & 1 \\
& L15R2 & 20 & 15 & 2 \\
& L15R3 & 20 & 15 & 3 \\
& L15R4 & 20 & 15 & 4 \\
& L15R5 & 20 & 15 & 5 \\
\hline Type-B & L10 & 15 & 10 & - \\
& L15 & 25 & 15 & - \\
\hline
\end{tabular}

Table 1. Shapes and dimensions of the specimen
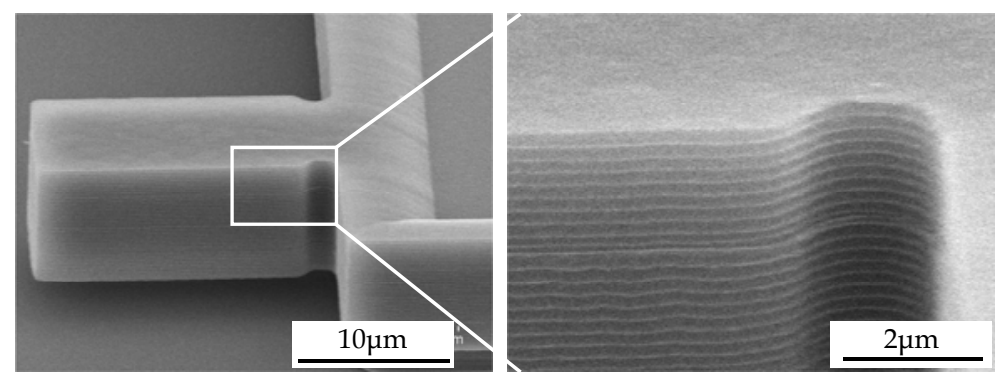

Fig. 2. Sidewall surface morphology of the $h=6.4[\mu \mathrm{m}]$ poly-Si specimen made by DRIE process 


\subsection{Strength test and stress analysis}

A dynamic ultra-micro hardness tester (Shimadzu DUH-W201) with a Berkovich diamond indenter is used for the bending tests. The test machine is for hardness tests but we can obtain the relationship between the load and the displacement with satisfactory accuracy by this machine. The test load speed is $1.421[\mathrm{mN} / \mathrm{sec}$.]. The bending tests are carried out at room temperature under the atmospheric environment.

In order to quantify the fracture of specimens by the applied stresses in the tests, threedimensional finite element elastic analyses are performed with Young's modulus: 148[GPa], Poisson's ratio: 0.2. The software used for this analysis is ANSYS 10.0. Figure 3 indicates the examples of FEM models of the specimens (Type-A, L15R1). For the Type-B specimen, the $1 \mu \mathrm{m}$ corner radius is taken into the model based on the microscopic observations mentioned above. The stress concentration factor of Type-B is close to that of Type-A, L15R3. The element sizes of the models are about $1 \mu \mathrm{m}$ in the overall region and are about $0.1 \mu \mathrm{m}$ in the stress concentration area near the notch root.

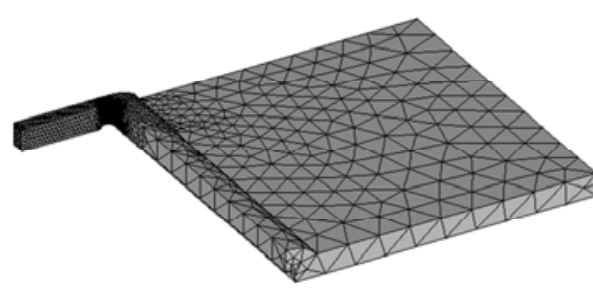

(a) Whole of the FEM model (1/2 model) section of the specimen

Fig. 3. Examples of the FEM model $(h=6.4[\mu \mathrm{m}], \mathrm{L} 15 \mathrm{R} 1)$.

\subsection{Surface roughness}

In order to investigate the stress concentration by the shape of the microscopic surface of a specimen, surface shapes were measured using the atomic force microscope (AFM) (VEECO $\mathrm{D}-3000)$. The region to measure was made into $1[\mu \mathrm{m}]$ four quarters. The upper surfaces of the specimens were measured by scanning in the specimen longitudinal direction, and the sidewall surface of the specimens scanned and measured the scarop bottom in the specimen longitudinal direction. The maximum stress concentration factor $K_{t}$ max which exists in a specimen was determined using the roughness of the measured surface. It is shown in 5.1 for details. In order to estimate the maximum stress concentration factor which exists in a specimen, the data of stress concentration factor determined by measurement was arranged using statistics of extreme [Gumbel, 1962].

\subsection{Effective area}

The following equations thought to be able to define an effective area $S$. The maximum stress $\sigma_{\max }$ of the structure calculated in FEM analysis and the $K_{t \max }$ calculated by roughness measurement are used. When the stress concentration shown in the Eq. (1) was taken into consideration, area on which the stress exceeding $\sigma_{\max }$ was made into the effective area.

$$
\sigma_{\max } \leq K_{t \max } \sigma
$$


The $S$ thought to expresses the effective area at the time of evaluating strength here. Within the range of an effective area, it can become fracture origin except the maximum stress working point by the stress concentration of structure by the surface roughness stress concentration.

\section{Bending test results}

Figure 3 shows examples of the relationship between load and displacement of the bending tests. In this figure, it is known that the polycrystalline silicon deformed elastically until final catastrophic failure in room temperature, showing a brittle nature. The relationship between load and displacement shows a little nonlinear behaviour. This is because of indentation to poly-Si of the indenter.

Figure 5 shows an expression of the test results by use of maximum peak stress $\sigma_{\max }$ in the notch root obtained by FEM analysis. In this figure, the plots of solid mark means the data of fracture specimens and the open mark means the data of non-fracture specimens due to the contact of free edge to the substrate surface before break. The displacement which contact occur changes with specimen, this may be because the residual stress and shape of the specimens has little difference respectively.

In Fig. 5, a tendency can be seen that the plots by the $\sigma_{\max }$ move down with the increase in notch radius because of the effect of the difference on the stress distribution pattern.

In order to investigate the scattering in the fracture strength obtained by a bending strength test and FEM analysis, fracture strength was plotted to Weibull probability paper [Weibull, 1951]. Weibull distribution is used for strength evaluation of a brittle material like the ceramics, and it is thought that Weibull distribution can estimate the strength of the poly-Si which is brittle material.

The function of two population parameters Weibull distribution can be expressed with the following equation.

$$
F=1-\exp \left\{-A_{E}\left(\frac{\sigma_{\mathrm{B}}}{\sigma_{0}}\right)^{m}\right\}
$$

In Eq. (2), $F$ : cumulative probability of failure, $\sigma_{0}$ : scale parameter, $m$ : shape parameter, respectively, $A_{E}$ is the effective area. For Weibull plots, Eq. (2) is changed as follows.

$$
\ln \ln \frac{1}{1-F}=m\left(\ln \sigma_{\mathrm{B}}-\ln \sigma_{0}\right)+\ln A_{E}
$$

Figure 6 shows the Weibull plots of bending strength for poly-Si. The non-fracture data are treated statistically [Johnson, 1964]. Figure 6 show the validity of using Weibull analysis for this study.

Figure 7 shows the scale parameters $\left(\sigma_{0}\right)$ of this study. If shapes of the specimen are different, then effective surface area is different. Then, the scale parameter is thought to be different. Figure 7(a) shows the validity of the effective surface. Figure 7(b) shows the same result. In Fig.7, $h=3.5[\mu \mathrm{m}]$ specimen shows different trend. We'll discuss about it later.

Figure 8 shows the result of shape parameter $(m)$. With effective surface area, Weibull parameters are shown as follows.

Equation (3) shows the shape parameter $(m)$ is independent on effective area $\left(A_{E}\right)$. Figure 8 shows the independency but for $h=3.5[\mu \mathrm{m}]$ specimen. Then, we found that the scatter in 
poly-Si bending strength for $h=3.5[\mu \mathrm{m}]$ specimen is smaller than that of $h=6.4,8.3[\mu \mathrm{m}]$ specimen because the $m$ of the $h=3.5[\mu \mathrm{m}]$ specimen are large.

Figure 9 shows the fracture surface and around the fracture surface of poly-Si of this study. Fig. 9(a) $(h=3.5[\mu \mathrm{m}])$ are different from Fig. $9(\mathrm{~b}, \mathrm{c})(h=6.4,8.3[\mu \mathrm{m}])$. This is because the etching processes for these specimens are different. The $h=6.4[\mu \mathrm{m}]$ and $8.3[\mu \mathrm{m}]$ specimens are made by same DRIE process, but $h=3.5[\mu \mathrm{m}]$ is made by another RIE process. Then the side surface condition of these specimen are different and the effect of effective area are thought to be different between $h=3.5[\mu \mathrm{m}]$ specimen and $h=6.4,8.3[\mu \mathrm{m}]$ specimen.

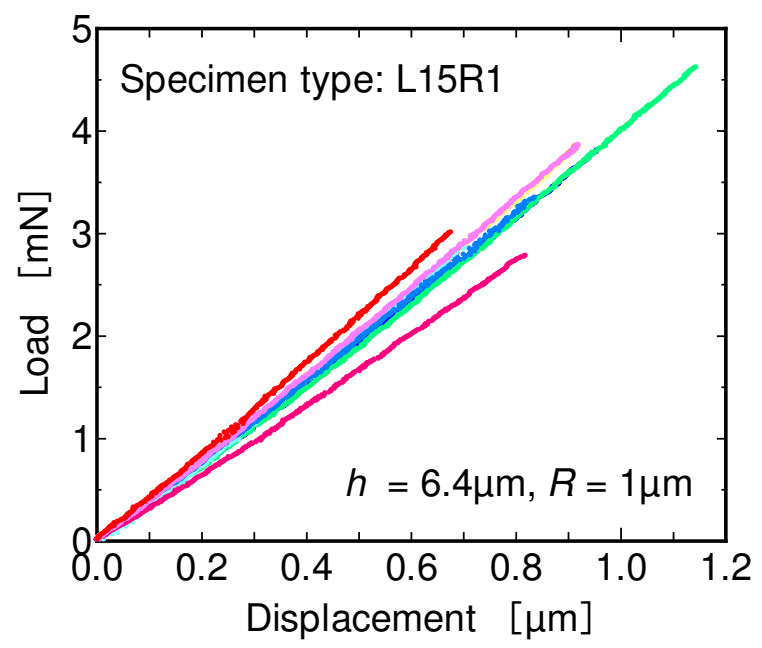

Fig. 4. Example of relationship between load and displacement.

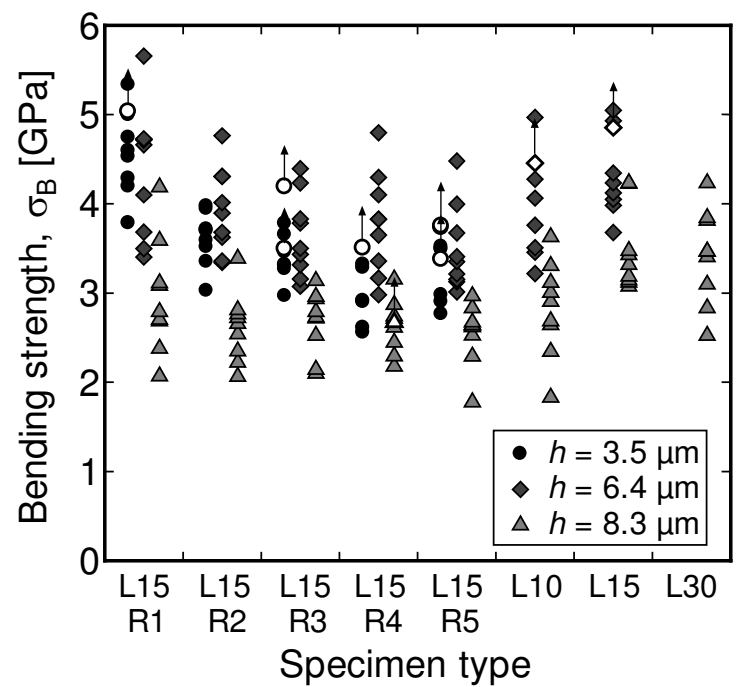

Fig. 5. Weibull plots of bending strength for poly-Si 


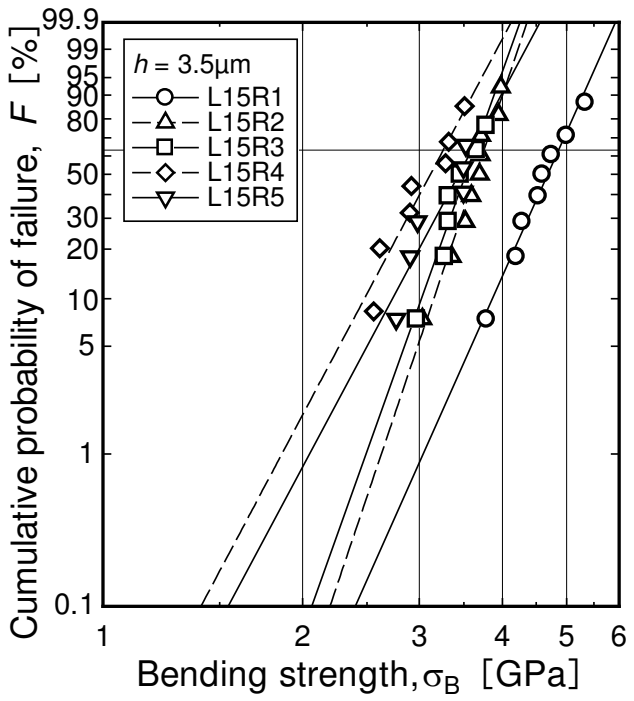

(a) $h=3.5[\mu \mathrm{m}]$ specimen

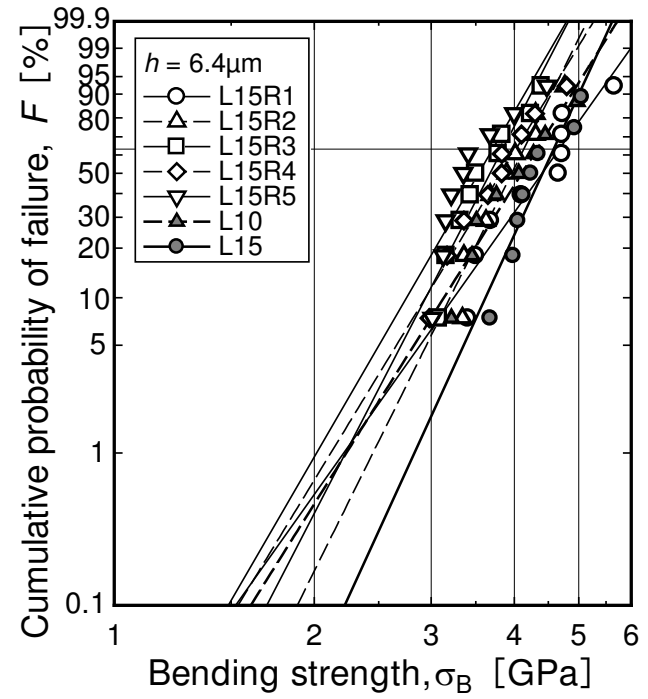

(b) $h=6.4[\mu \mathrm{m}]$ specimen

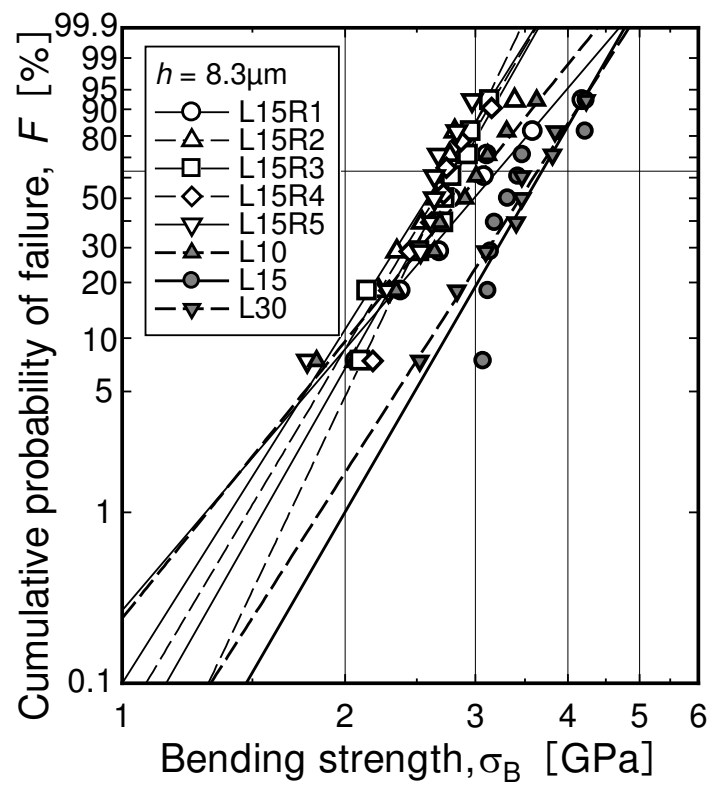

(c) $h=8.3[\mu \mathrm{m}]$ specimen

Fig. 6. Weibull plots of bending strength for poly-Si 


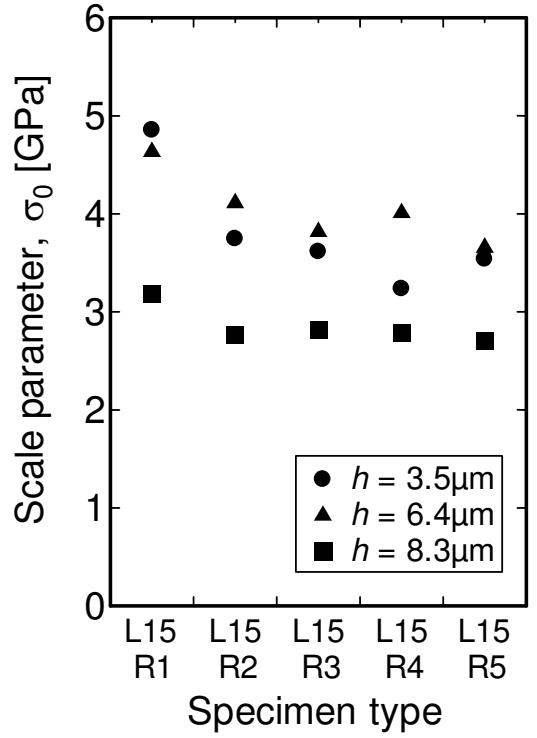

(a) specimen type dependency.

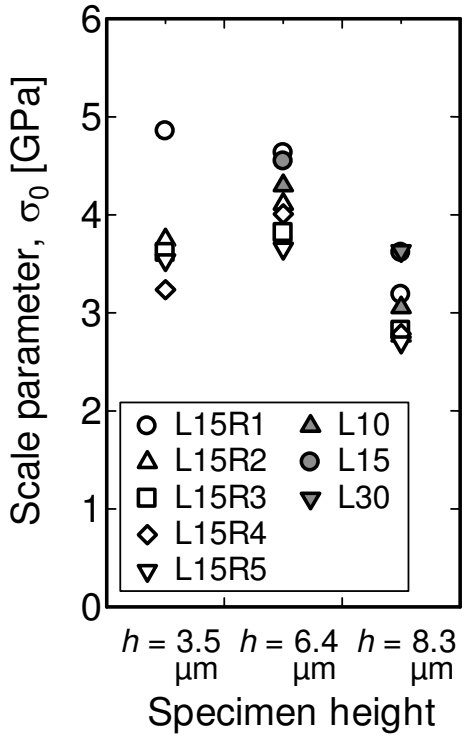

(b) specimen height dependency

Fig. 7. Scale parameters of the bending strength for poly-Si.

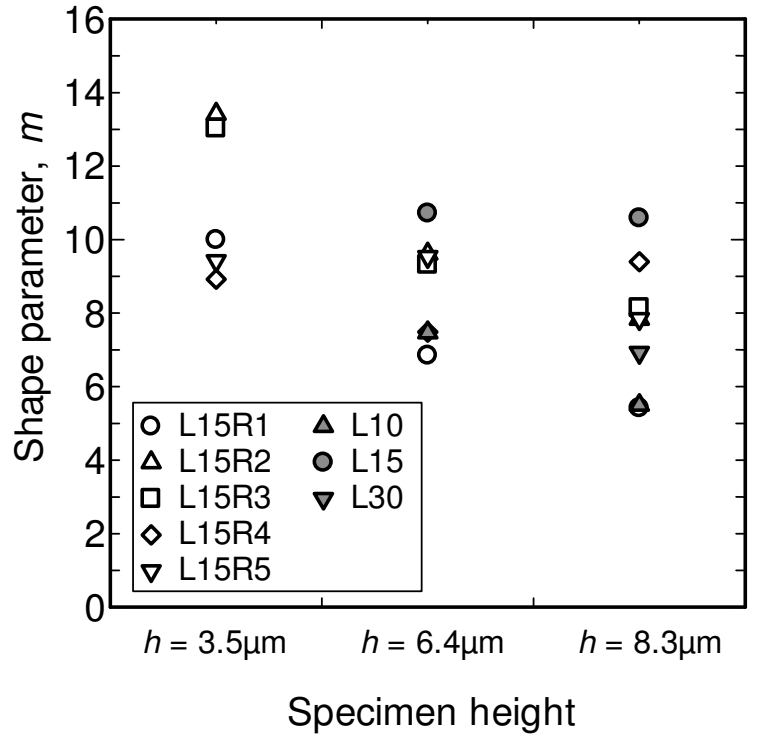

Fig. 8. Shape parameters of the bending strength for poly-Si. 

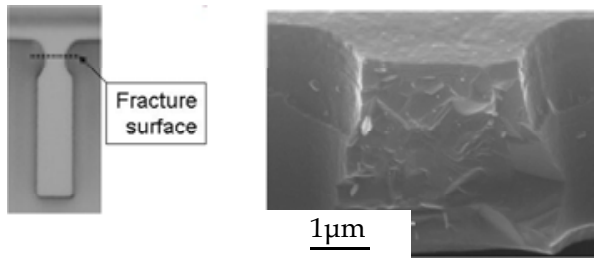

(a) $h=3.5[\mu \mathrm{m}]$, L15R3.

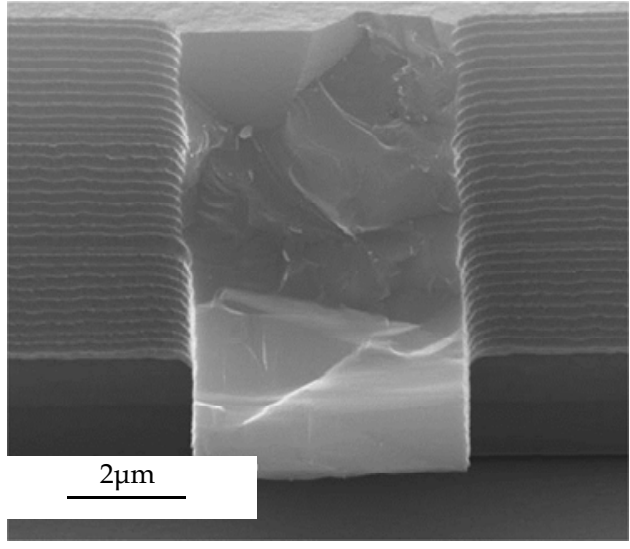

(b) $h=6.4[\mu \mathrm{m}]$, L30.

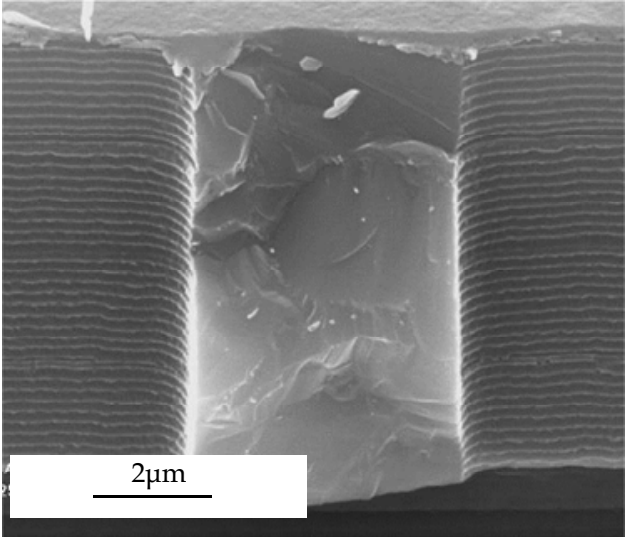

(c) $h=8.3[\mu \mathrm{m}], \mathrm{L} 15$.

Fig. 9. Fracture surface and surface image of poly-Si for this study.

\section{Fracture toughness and fracture angle}

\subsection{Fracture toughness}

In order to make clear the reason of the strength scattering, analysis of the fracture surface by SEM are performed. If the variation of the strength is dependent on the initial defect size, then calculated fracture toughness is thought to be same. Figure 10 show one example of the analysis. In this figure, in the area of fracture origin, a mirror zone [Hull, 1999] came under observation. Then, we assume that the mirror zone is initial defect, stress intensity factors for the mirror zone are calculated by quarter-elliptical crack in a plate under bending mode stress distribution [Murakami, 1992]. Figure 11 shows the results. The average of the fracture toughness is $2.1[\mathrm{MPa} \sqrt{\mathrm{m}}$ ]. Comparing this value with other reports [Hahn et al., 2000; Son et al., 2004], the value found to be about double. Then area of mirror zone is not same as area of initial defect. But Figure 11 shows that the fracture toughness is independent on specimen shape and the value is constant to some extent. Then area of mirror zone assumed to be proportional to the initial defect.

\subsection{Fracture angle}

More fractographic analysis is performed. Then, we found that the angle of mirror zone is different from the principal stress surface. An example of the observation result and the 
definition of the angle $(\theta)$ are shown in Fig.12. Figure 13 shows the relationship between fracture toughness using stress and mirror zone and the angle. In this figure dependency of the fracture toughness on the angle can be seen. The reasons are thought as follows. (1) The poly-Si crystal on the fracture origin area are different from principal stress direction (2) the poly-Si grain boundary on the fracture initiation area are different from principal stress direction.

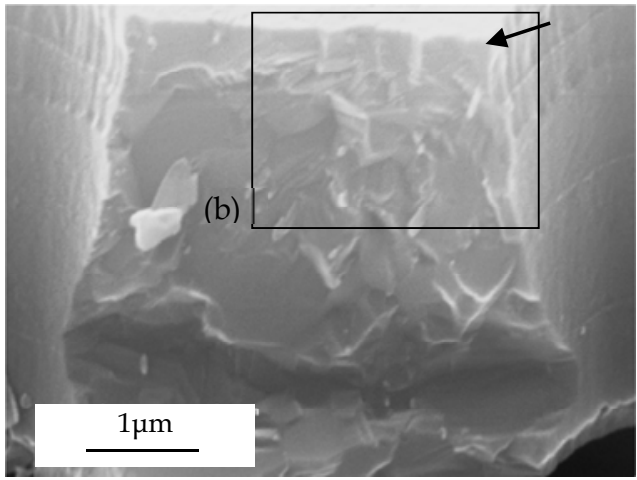

(a) Macroscopic view of fracture surface(arrow shows the fracture origin)

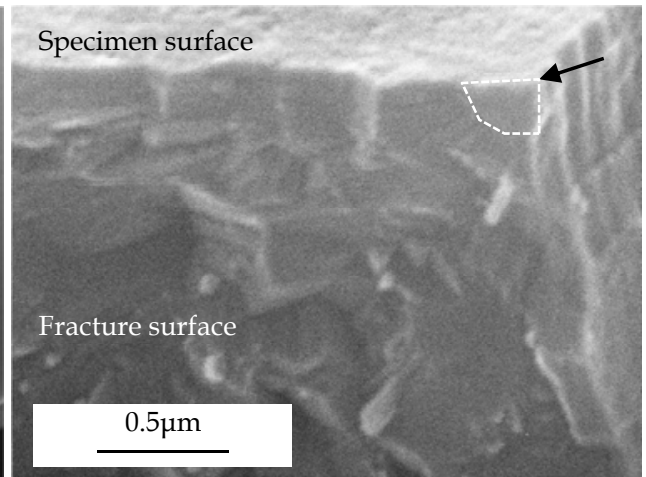

(b) Magnification of fracture origin (dashed line shows the mirror zone)

Fig. 10. Example of fracture surface $(h=3.5[\mu \mathrm{m}], \mathrm{L} 15 \mathrm{R} 3)$

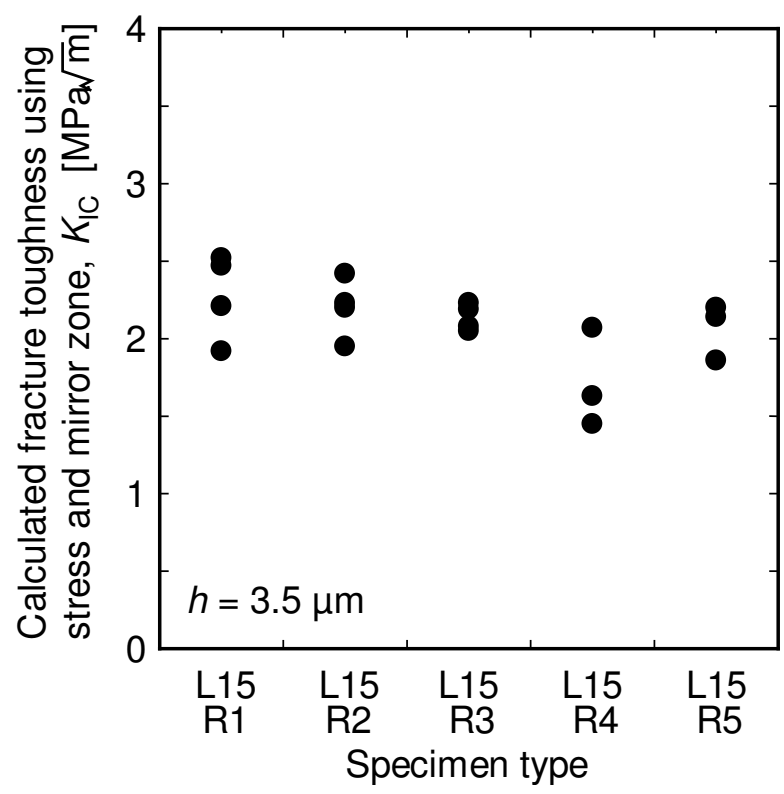

Fig. 11. Scale parameters of the bending strength for poly-Si $(h=3.5[\mu \mathrm{m}])$. 


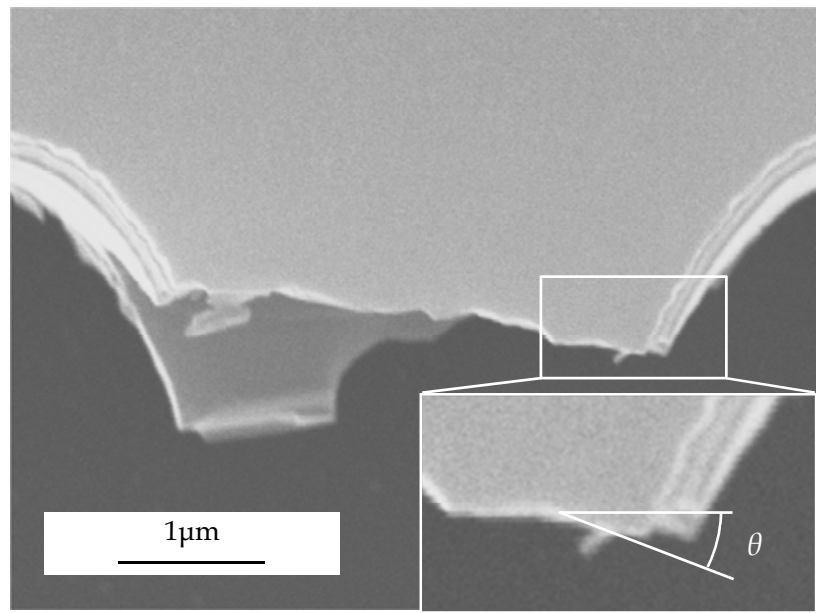

Fig. 12. Definition of fracture surface (mirror zone) angle.

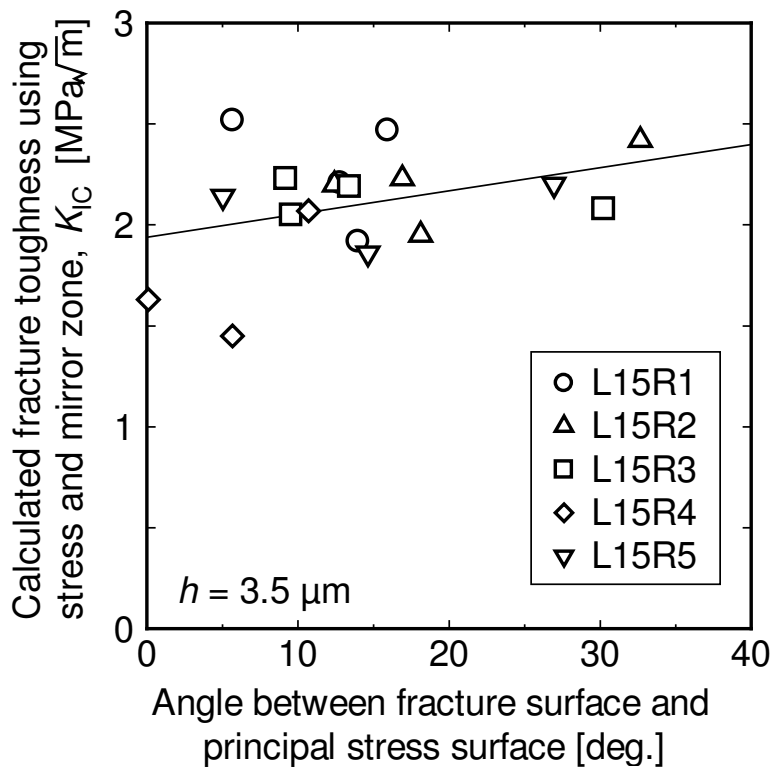

Fig. 13. Angle dependency of fracture toughness $(h=3.5[\mu \mathrm{m}])$.

\section{Effective area and application to design}

\subsection{Effective area definition and calculation results}

The stress concentration factors on the specimen surface were determined based on the result of surface roughness measurement by AFM. As shown in Fig. 2, difference occurs in the surface shape of the upper surface and the sidewall surface by the difference in the manufacturing technique. Figure 14 indicates an example of the difference in surface 
roughness of the $h=6.4[\mu \mathrm{m}]$ specimen obtained by AFM, and Fig. 15 indicates the example of surface section of the scarop bottom on the sidewall surface.

Using the measurement result of the surface roughness, the stress concentration factors $K_{t}$ of the specimen were calculated. As shown in Fig. 14, the appearance present complicated shapes, therefore FEM analysis is necessary to calculate an accurate stress concentration factors. In this report, in order to simplify, the interference effects by the multiple notches were ignored and the stress concentration factors $K_{t}$ were determined from width $(a)$ and depth $(b)$ from the roughness measurements using the following equations supposing the equivalent ellipse as shown in Fig. 15.

$$
K_{t}=1+\frac{2 a}{b}
$$

The maximum stress concentration factor $K_{t \max }$ which exists in a specimen based on the data of the measured stress concentration factor is estimated using the statistics of extreme. Figure 16 shows the extreme values probability paper. The horizontal axis is the stress concentration factor $K_{t j}$ obtained by the Eq. (4). The vertical axis is the reduced variates $y_{j}$ calculated by the following equation which is a formula of the statistics of extreme.

$$
\begin{gathered}
F_{j}=\frac{j}{n+1}, \quad y_{j}=-\ln \left\{-\ln F_{j}\right\} \\
(j=1,2,3, \ldots, \mathrm{n} \quad \mathrm{n}: \text { Number of inspections })
\end{gathered}
$$

The approximate expression was calculated using the least square method from the obtained distribution. The maximum stress concentration factor which substitutes the return period $T$ for the following equations, and $K_{t \max }$ exist in a specimen is estimated.

$$
y=-\ln \left\{-\ln \left(\frac{T-1}{T}\right)\right\}, \quad y=\alpha K_{t \max }+\beta
$$

When determining the return period $T$, evaluation area was made equal to the effective area. The relation between evaluation area and the return period are defined using the following equations. ( $S_{0}$ : inspection area)

$$
\begin{gathered}
T_{i}=\frac{S_{i}+S_{0}}{S_{0}}, \quad S<10 S_{0} \\
T_{i}=\frac{S_{i}}{S_{0}}, \quad S>10 S_{0}
\end{gathered}
$$

In order to bring evaluation area close to an effective area, calculation performed repeatedly. The computational procedure is as follows. Fig. 17 indicates a computational procedure outline.

1. Define $T_{0}$ by the evaluation area to the extent of the whole specimen is included enough

2. Calculate $\mathrm{Kt}$ i from defined $T_{0}$

3. Calculate assumed effective area $S_{i}$ from Eq. (1) and FEM

4. Calculate $T_{i}, S_{i}$ as evaluation area

5. Calculate $K_{t i+1}$ from $T_{i}$

6. Compare $K_{t i}$ and $K_{t i+1}$. If $K_{t i} /\left(K_{t i+1}\right)>0.99$, then define $S_{i}$ as effective area

7. If not $K_{t i} /\left(K_{t i+1}\right)>0.99$, repeat the process after 3$)$. 


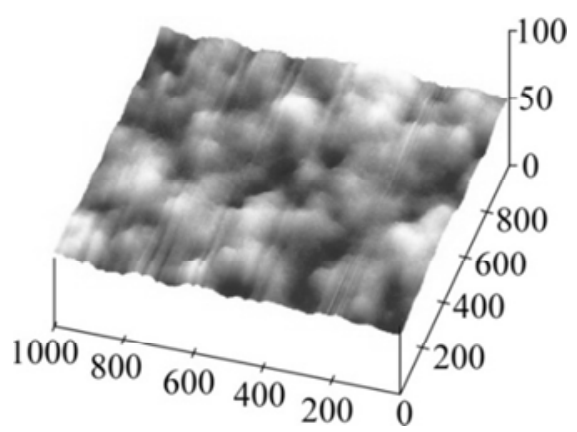

(a) Top surface

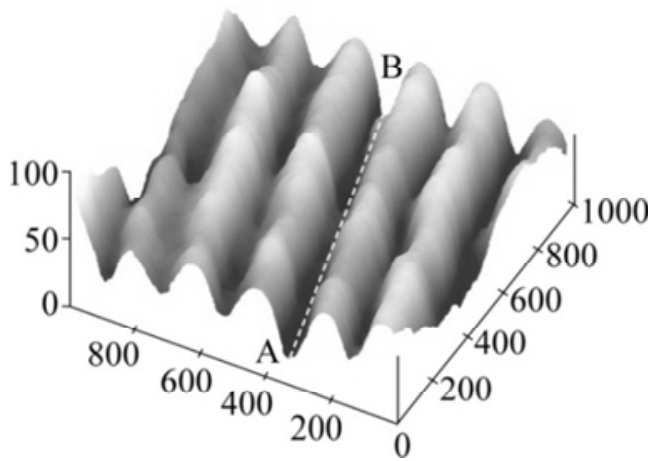

(b) Sidewall surface

Fig. 14. Surface morphology of top and sidewall (unit: $\mathrm{nm})(h=6.4[\mu \mathrm{m}])$.

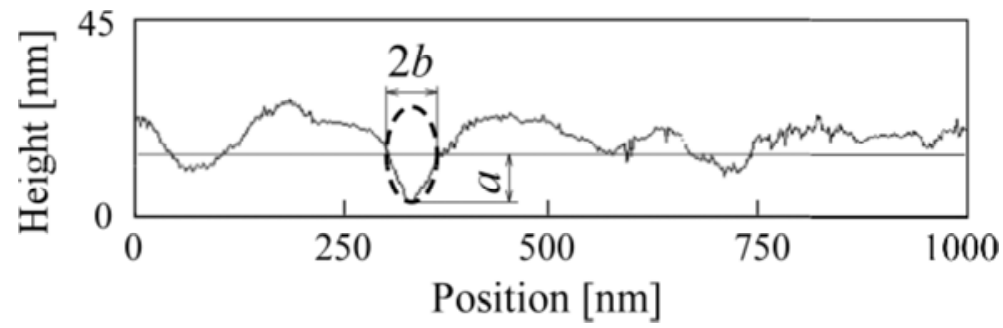

Fig. 15. Surface roughness example of sidewall (Fig. 14 A-B).

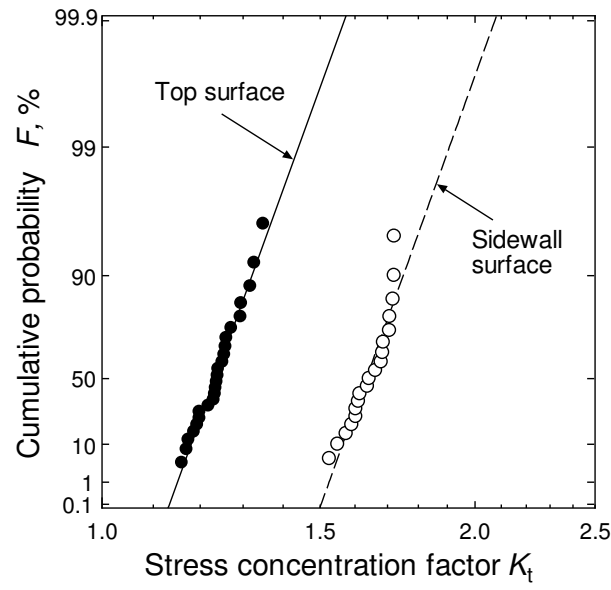

Fig. 16. Variation of stress concentratio factor $K_{t}$.

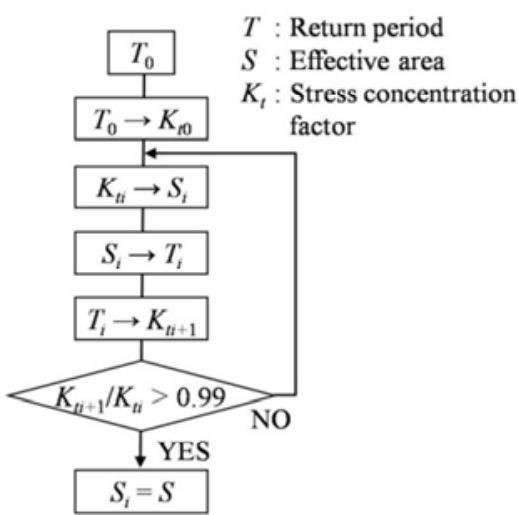

Fig. 17. Schematic diagram of deciding $S$ from $T$ and $K_{t}(h=6.4[\mu \mathrm{m}])$. 


\begin{tabular}{|c|c|c|c|}
\hline \multirow[t]{2}{*}{$\begin{array}{l}\text { Specimen } \\
\text { type }\end{array}$} & \multicolumn{2}{|c|}{$\begin{array}{c}\text { Maximum stress } \\
\text { concentration factor } \\
K_{t \max }\end{array}$} & \multirow[t]{2}{*}{$\begin{array}{c}\text { Effective } \\
\text { area } \\
S\left[\mu \mathrm{m}^{2}\right]\end{array}$} \\
\hline & Top surface & Sidewall surface & \\
\hline L15R1 & 1.22 & 1.79 & 4.02 \\
\hline L15R2 & 1.28 & 1.82 & 8.01 \\
\hline L15R3 & 1.34 & 1.84 & 13.7 \\
\hline L15R4 & 1.39 & 1.86 & 22.7 \\
\hline L15R5 & 1.39 & 1.85 & 22.8 \\
\hline L10 & 1.20 & 1.78 & 3.57 \\
\hline L15 & 1.21 & 1.78 & 3.47 \\
\hline
\end{tabular}

Table 2. Result of calculations, $K_{t \max }$ and $S(h=6.4[\mu \mathrm{m}])$.

In this study, it calculated as initial return period value $T_{0}=10000$. Table 2 shows the obtained $K_{t} \max$ and $S$.

\subsection{Effective area and fracture origin}

Figure 18 indicates the example in the structure of the effective area. Figure 18 shows that the region of effective area where fracture origin may exist has extended to the specimen sidewall. Fracture surface observation of the specimen was carried out, and the example to which fracture origin exists in the sidewall was observed. Figure 19 shows an example. The scattering in fracture origin is shown in Fig. 20. It turns out that fracture origin varies within an effective area.

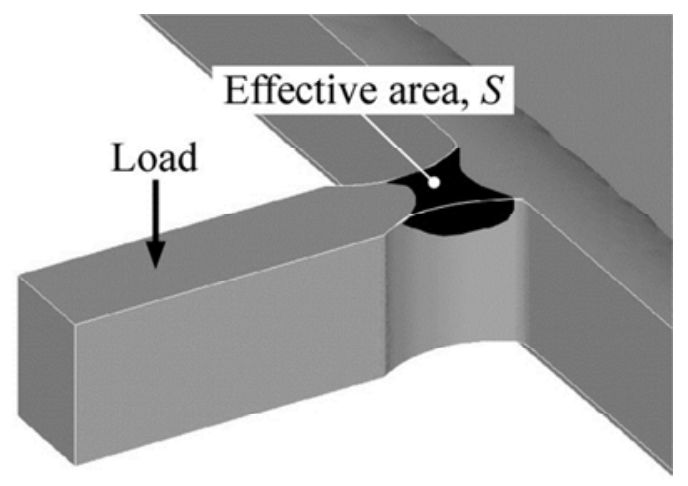

Fig. 18. Calculated effective area $S$ (Specimen type: L15R5, $h=6.4[\mu \mathrm{m}])$.

\subsection{Application to design}

Bending strength (maximum stress $\sigma_{\max }$ at the time of fracture) $\sigma_{B}$ and the maximum stress concentration factor $K_{t} \max$ were fitted to the Eq. (1) and the effective area was determined. Figure 21 shows the relationship between bending strength and the effective area. Average values of the test data $(N=8)$ were used for $\sigma_{B}$. The tendency bending strength becomes small as the effective area increased can be seen.

The equation of Weibull distribution which generally took the effective volume $V$ into consideration same as Section 3 is shown as follows. 


$$
F=1-\exp \left\{-V\left(\frac{\sigma_{\mathrm{B}}}{\sigma_{0}}\right)^{\mathrm{m}}\right\}
$$

Eq. (9) can be expressed as follows.

$$
\ln \ln \frac{1}{1-F}=m\left(\ln \sigma_{\mathrm{B}}-\ln \sigma_{0}\right)+\ln V
$$

It turns out in the Eq. (10) that the effective volume $V$ acts as a value which does not involve at the shape parameter $m$ which shows the level of scattering. Since an effective volume did not participate in scattering, it extrapolated to the reliability needed for a design using the average of the shape parameter determined from the experimental result $\sigma_{B}$. In Fig. 21, an extrapolation example in the case of $F=0.001$, the relationship between $\sigma_{\mathrm{B}}$ and $S$ are shown.

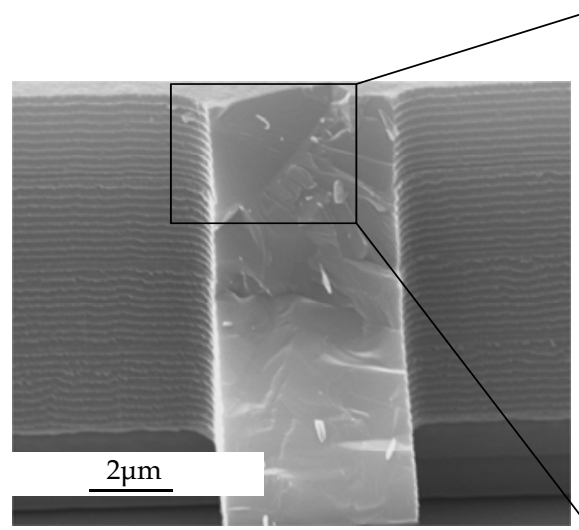

(a) Whole fracture surface

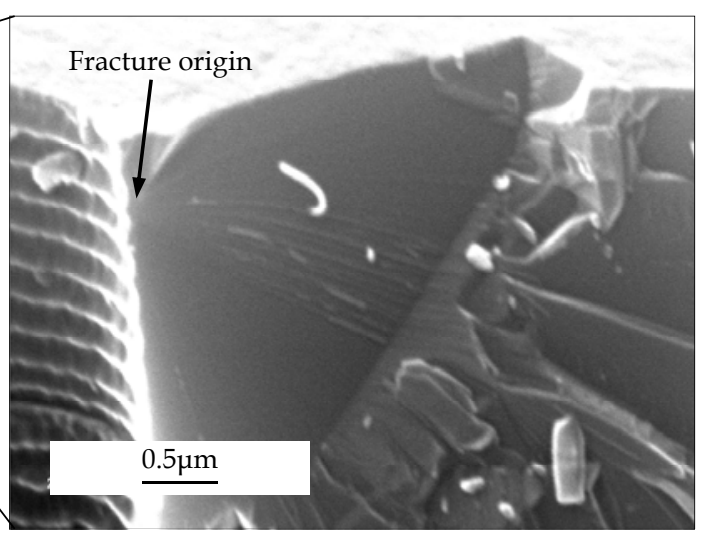

(b) Magnification of fracture origin

Fig. 19. Fracture origin on the sidewall surface $(h=6.4[\mu \mathrm{m}])$.

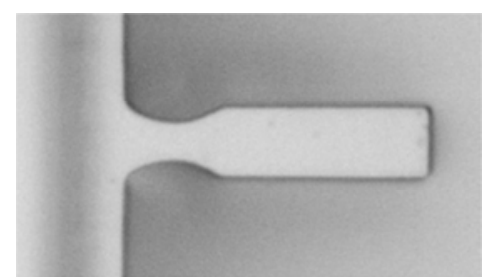

(a) Before test

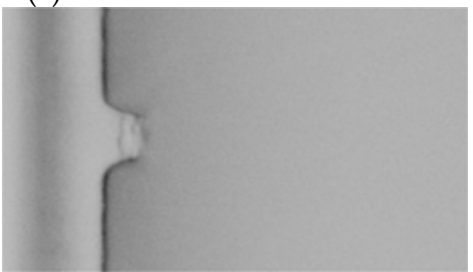

(c) After test, $\sigma_{B}=3.41[\mathrm{GPa}]$

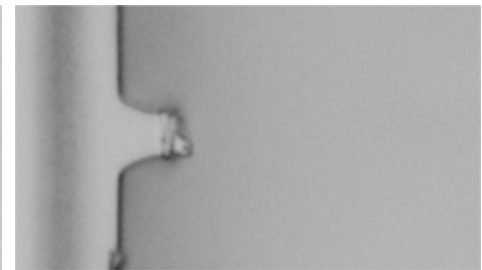

(b) After test, $\sigma_{B}=3.15[\mathrm{GPa}]$

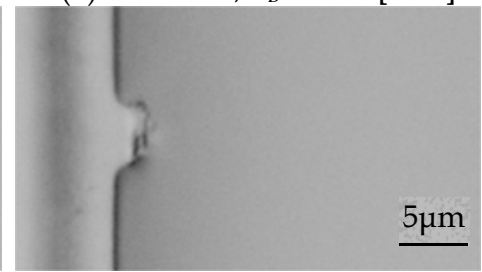

(d) After test, $\sigma_{B}=3.67[\mathrm{GPa}]$

Fig. 20. Variation of fracture points, Specimen type: L15R5, $h=6.4[\mu \mathrm{m}]$. 


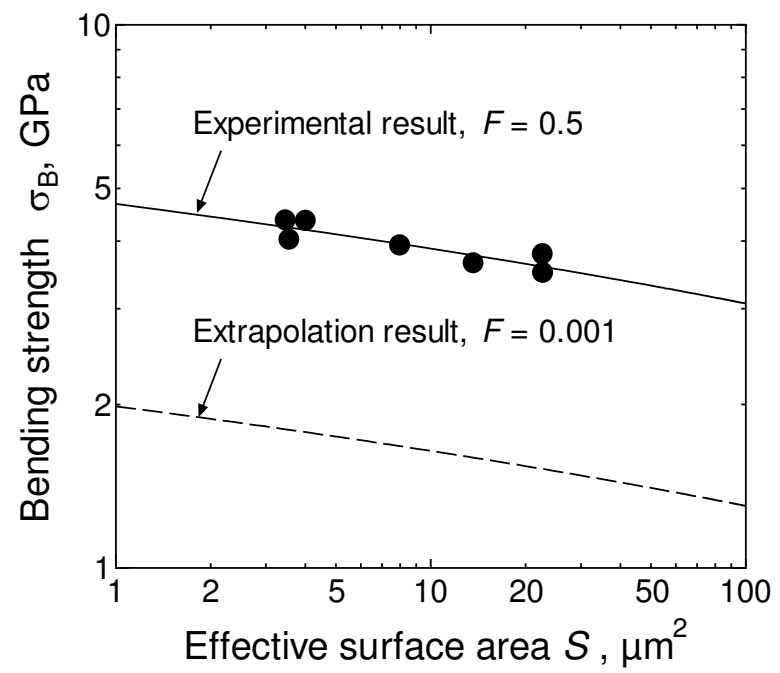

Fig. 21. Relationship between the bending strength and effective area

\section{Conclusion}

In order to propose the static strength design criteria of the poly-Si structure which has a microscopic dimension, the bending test, surface roughness measurement, FEM analysis, the Weibull statistical analysis, statistics of extreme analysis, and fracture analysis of a cantilever beam were conducted.

The obtained results are as follows.

1. By Weibull analysis, we found that the scatter in poly-Si bending strength made by RIE process is smaller than that of DRIE process.

2. Poly-Si strength is scattered. It depends on surface condition, crystal or grain boundary direction and some other.

3. The definition method of the quantitative effective area in bending cantilever beam was shown to the poly-Si with which the surface roughness on the upper surface and the surface of the sidewall differs.

4. Bending strength depends on the effective area definition are shown.

5. The static strength design criteria in consideration of the scattering in the strength using two parameters, the bending strength (maximum stress at the time of fracture) and the effective area, was proposed.

\section{References}

Chen, K. S.; Ayón, A. A.; Zhang X. \& Spearing, S. M. (2002). Effect of Process Parameters on the Surface Morphology and Mechanical Performance of Silicon Structures After Deep Reactive Ion Etching (DRIE), IEEE Journal of Microelectromechanical Systems, Vol. 11, No. 3, pp. 264-275, ISSN 1057-7157 
Greek, S.; Ericson, F.; Johansson, S. \& Schweitz, J.-Å. (1997). In situ tensile strength measurement and Weibull analysis of thick film and thin film micromachined polysilicon structures, Thin Solid Films, Vol. 292, pp. 247-254, ISSN 0040-6090

Gumbel, E. J. (1962). Statistic of Extremes, Columbia Univ. Press, New York

Hull, D. (1999). Fractography, Cambridge University Press, ISBN 0521640822, Cambridge, pp. 121-129.

Johnson, L. G. (1964). The Statistical Treatment of Fatigue Experiments, Elsevier, New York

Kahn, H.; Tayebi, N.; Ballarini, R.; Mullen R. L. \& Heuer, A. H. (2000). Fracture toughness of polysilicon MEMS devices, Sensors and Actuators A, Vol. 82, pp. 274-280, ISSN 09244247

Kapels, H.; Aigner, R. \& Binder, J. (2000). Fracture strength and fatigue of polysilicon determined by a novel thermal actuator, IEEE Transactions on Electron Devices, Vol. 47, pp. 1522-1528, ISSN 0018-9383

Muhlstein, C. L.; Howe R. T. \& Ritchie, R. O. (2004). Fatigue of Polycrystalline Silicon for Microelectromechanical Systems: Crack Growth and Stability under Resonant Loading Conditions, Mechanics of Materials, Vol. 36, pp. 13-33, ISSN 0167-6636

Murakami ,Y. Eds. (1992). Stress Intensity Factors Handbook Vol.3, Soc. Materials Sci., Japan \& Pergamon Press, pp. 591-597

Najafi, K. (2000). Micromachined Micro Systems: Miniaturization Beyond Micro-electronics, Proc. 2000 Symposium on VLSI Circuits Digest of Technical Papers, pp. 6-13

Namazu, T.; Isono Y. \& Tanaka, T. (2000). Evaluation of Size Effect on Mechanical Properties of Single Crystal Silicon by Nano-Scale Bending Test using AFM, IEEE Journal of Microelectromechanical Systems, Vol. 9, pp. 450-459, ISSN 1057-7157

Senturia, S. D. (2000). Microsystem Design, Kluwer Academic Publishers, ISBN 0792372468, Dordrecht

Sharpe Jr., W. N.; Jackson, K. M.; Hemker K. J. \& Xie, Z. (2001). Effect of Specimen Size on Young's Modulus and Fracture Strength of Polysilicon, IEEE Journal of Microelectromechanical Systems, Vol. 10, pp. 317-326, ISSN 1057-7157

Son, D.; Kim, J.; Lim T. W. \& Kwon, D. (2004). Evaluation of fracture properties of silicon by combining resonance frequency and microtensile methods, Thin Solid Films, Vol. 468, pp. 167-173, ISSN 0040-6090

Tsuchiya, T.; Tabata, O.; Sakata J \& Taga, Y. (1998). Specimen size effect on tensile strength of surfacemicromachined polycrystalline silicon thin films, IEEE Journal of Microelectromechanical Systems, Vol. 7, pp. 106-113, ISSN 1057-7157

Weibull, W. (1951). A statistical distribution function of wide applicability, Transactions ASME Journal of Applied Mechanics, Vol. 18, pp. 293-297 


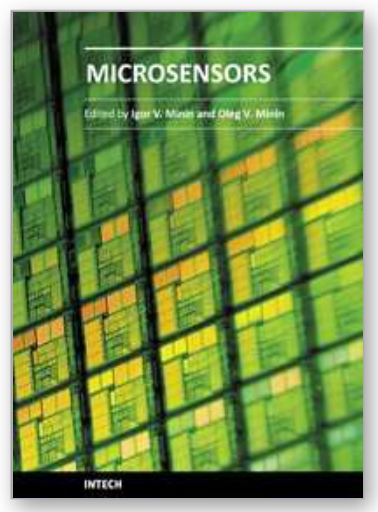

\author{
Microsensors \\ Edited by Prof. Igor Minin
}

ISBN 978-953-307-170-1

Hard cover, 294 pages

Publisher InTech

Published online 09, June, 2011

Published in print edition June, 2011

This book is planned to publish with an objective to provide a state-of-art reference book in the area of microsensors for engineers, scientists, applied physicists and post-graduate students. Also the aim of the book is the continuous and timely dissemination of new and innovative research and developments in microsensors. This reference book is a collection of 13 chapters characterized in 4 parts: magnetic sensors, chemical, optical microsensors and applications. This book provides an overview of resonant magnetic field microsensors based on MEMS, optical microsensors, the main design and fabrication problems of miniature sensors of physical, chemical and biochemical microsensors, chemical microsensors with ordered nanostructures, surfaceenhanced Raman scattering microsensors based on hybrid nanoparticles, etc. Several interesting applications area are also discusses in the book like MEMS gyroscopes for consumer and industrial applications, microsensors for non invasive imaging in experimental biology, a heat flux microsensor for direct measurements in plasma surface interactions and so on.

\title{
How to reference
}

In order to correctly reference this scholarly work, feel free to copy and paste the following:

Shigeru Hamada, Kenji Hasizume, Hiroyuki Nakaura and Yoshihide Sugimoto (2011). Strength Reliability of Micro Polycrystalline Silicon Structure, Microsensors, Prof. Igor Minin (Ed.), ISBN: 978-953-307-170-1, InTech, Available from: http://www.intechopen.com/books/microsensors/strength-reliability-of-micro-polycrystallinesilicon-structure

\section{INTECH}

open science | open minds

\section{InTech Europe}

University Campus STeP Ri

Slavka Krautzeka 83/A

51000 Rijeka, Croatia

Phone: +385 (51) 770447

Fax: +385 (51) 686166

www.intechopen.com

\section{InTech China}

Unit 405, Office Block, Hotel Equatorial Shanghai

No.65, Yan An Road (West), Shanghai, 200040, China

中国上海市延安西路65号上海国际贵都大饭店办公楼405单元

Phone: +86-21-62489820

Fax: +86-21-62489821 
(C) 2011 The Author(s). Licensee IntechOpen. This chapter is distributed under the terms of the Creative Commons Attribution-NonCommercialShareAlike-3.0 License, which permits use, distribution and reproduction for non-commercial purposes, provided the original is properly cited and derivative works building on this content are distributed under the same license. 